\title{
ON THE DETERIORATION OF A GROUNDED ICEBERG
}

\author{
By $\mathrm{S}$. VENKATESH
}

(Atmospheric Environment Service, Downsview, Ontario M3H 5T4, Canada)

ABSTRACT. This paper examines the deterioration of an iceberg grounded outside St. John's Harbour, Newfoundland, Canada, in terms of its initial velocity prior to grounding. Theoretical expressions for the lifting of the iceberg and hence its buoyancy loss during grounding are derived as a function of initial iceberg velocity and ocean-bottom slope. Wave erosion and calving are two of the most significan mechanisms for iceberg deterioration. With wave erosion occurring on the seaward side of the grounded iceberg, model simulations are compared with observational data from a field study conducted on the grounded iceberg between 10 and 17 June 1983. Model-simulated time of reflotation of the iceberg agrees with observations, for initial iceberg velocity of $0.3-0.5 \mathrm{~m} / \mathrm{s}$. Model simulations of the deterioration of the iceberg beyond the point of re-flotation are also compared with observations. Allowing for a $10 \%$ error in the observed above-water volume of the iceberg on 10 June, the model-simulated mass losses are in good agreement with observations. Best results are obtained for the model initialized with data observed on 14 June 1983 , the first day for which detailed observational data are available following re-flotation of the iceberg.

RÉsUMÉ. De la détérioration d'un iceberg après son atterrissage. Ce papier examine la détérioration d'un iceberg échoué au voisinage de Port de St John's, Newfoundland, Canada, en fonction de sa vitesse initiale au moment du contact avec le sol. Des expressions théoriques sur le glissement de l'iceberg et sa perte de flottaison au cours de l'atterrissage sont établis en fonction de sa vitesse initiale et de la pente du fond de l'océan. L'érosion par les vagues et le vêlage sont les deux des mécanismes prépondérants de sa détérioration. Pour l'érosion par les vagues qui s'exerce du côté du large, des modèles de simulations sont comparés avec les données d'observation pour une étude de terrain sur un iceberg échoué entre le 10 et 17 Juin 1983. Un temps simulé de remise à flots concorde avec les observations pour des vitesses d'atterrissage de 0,3 à $0,5 \mathrm{~m} / \mathrm{s}$. Des simulations

\section{INTRODUCTION}

In a recent paper, Venkatesh and others (1985) examined the deterioration of two icebergs that were grounded just outside the harbour at St. John's, Newfoundland. The field study, carried out over a 2 week period in June 1983, was described and the observed deterioration compared with simulations from the icebergdeterioration model of El-Tahan and others (1984). For the first iceberg, which had an initial mass of about 1.6 million tonnes, the model-simulated deterioration over a $13 \mathrm{~d}$ period was in good agreement with observations. However, for the second iceberg, with an initial mass of about 0.8 million tonnes, there were some large differences between modelsimulated and observed deterioration. A significant part of this difference occurred between 10 and 14 June with the difference between observed and model-simulated mass being over $30 \%$ of the observed mass on 14 June. The possible reasons for this difference, as noted by Venkatesh and others (1985), included (i) the errors in estimates of mass loss due to deterioration introduced by the change in orientation of the iceberg between 10 and 14 June, and (ii) mass losses possibly caused by deterioration mechanisms not accounted for in the model (e.g. thermal cracking). modélisées de la détérioration d'un iceberg non remis à flot sont aussi comparées avec les observations. Avec une marge d'erreur de $10 \%$ sur l'estimation du volume non immergé de l'iceberg au 10 Juin le modèle de perte de masse est en bonne concordence avec les observations. On obtient de bien meilleurs résultats avec un modèle débutant sur les données du 14 Juin 1983, lors du premier jour où l'on dispose de données détaillées d'observation à la suite de la remise à flot de l'iceberg.

Zusammenfassung. Der Verfall eines gestrandeten Eisberges. Die Arbeit untersucht den Verfall eines ausserhalb des Hafens von St. John's, Neufundland, Kanada, gestrandeten Eisberges im Vergleich zu dessen ursprünglicher Geschwindigkeit vor dem Aufsitzen. Theoretische Ausdrücke für die Hebung des Eisberges und als Folge davon den Verlust an Auftrieb während des Aufsitzens werden als eine Funktion der ursprünglichen Eisberggeschwindigkeit und der Neigung des Meeresbodens hergeleitet. Die bedeutsamsten Mechanismen für den Eisbergverfall sind die Wellenerosion und das Kalben. Wellenerosion tritt an der Seeseite des gestrandeten Eisbergs auf; die Modellsimulationen hierfür werden mit Beobachtungsdaten aus einer Feldstudie am Eisberg zwischen dem 10. und 17. Juni 1983 verglichen. Die im Modell simulierte Zeit für das Wiederaufschwimmen des Eisbergs stimmt mit den Beobachtungen überein, bei einer ursprünglichen Geschwindigkeit des Eisbergs von $0,3-0,5 \mathrm{~m} / \mathrm{s}$. Modellsimulationen des Verfalls des Eisbergs nach dem Wiederaufschwimmen werden ebenfalls mit Beobachtungen verglichen. Räumt man einen Fehler von $10 \%$ im Überwasservolumen des Eisbergs am 10. Juni ein, so stehen die modellsimulierten Massenverluste in guter Übereinstimmung mit den Beobachtungen. Die besten Ergebnisse liefert das Modell, das von den Beobachtungsdaten vom 14. Juni 1983 ausgeht, dem ersten Tag, für den ausführliches Beobachtungsmaterial im Gefolge des Wiederaufschwimmens des Eisberges vorliegen.

The object of this paper is to examine the implications and impact of the orientation change on the deterioration of the iceberg. Formulations of the lifting of the iceberg during grounding are derived as a function of the initial velocity of the iceberg. Deterioration of the grounded iceberg in the light of lifting is examined. Model simulations of the time for re-flotation of the iceberg are compared with observations. Deterioration of the iceberg beyond the point of re-flotation is also examined.

\section{DETERIORATION OF A FLOATING ICEBERG}

The important mechanisms influencing the deterioration of an iceberg (see White and others, 1980) include solar insolation, buoyant vertical convection, forced convection in air and water, wave erosion, and calving of the resulting overhanging ice slabs. While the other terms are selfexplanatory, buoyant vertical convection is the result of temperature and salinity differences between the iceberg melt water and the sea-water. El-Tahan and others (1984) have shown that for a floating iceberg wave erosion and calving together account for more than $80 \%$ of the total mass loss. Iceberg water-line melt rate $V_{\text {mw }}$ per deg of water temperature due to wave erosion is a function of the 
mean height $H$ and period $P$ of the waves, and the roughness height $R$ of the iceberg surface. It is given by the relationship

$$
V_{\mathrm{mw}} \times P / H=0.000146(R / H)^{0.2} .
$$

Calving of the overhanging slab (overhang being caused by wave erosion) occurs when the overhang exceeds a critical length $F_{\ell}$ depending on the wave height and thickness of the overhanging slab. The failure length $F_{\ell}$ is given by

$$
F_{l}=0.33\left(37.5 H+t^{2}\right)^{1 / 2}
$$

where all lengths are in meters. These and other deterioration mechanisms have been described in detail by El-Tahan and others (1984).

Application of the model to the deterioration of two icebergs grounded outside St. John's harbour in Newfoundland has been described in detail by Venkatesh and others (1985). In that study the masses of the icebergs were computed from stereophotographs of the above-water part of the icebergs and their density. In those calculations it was implicitly assumed that the iceberg velocity prior to grounding and hence the lifting of the iceberg during grounding was negligible. Thus, the ratio of above-water to under-water mass of the iceberg was known, it being a direct function of the ice and sea-water densities. The assumption also implies that, as the iceberg deteriorates, it will re-adjust to maintain the above-water to under-water mass ratio. If the iceberg is large, as was the case with one of the icebergs in the St. John's field study, the mass loss in short periods of time of the order of a few days will be a relatively small fraction of the total mass. This will require only a small re-adjustment in the flotation of the iceberg and, depending on the ocean-bottom slope and the forces moving the iceberg, it can remain grounded in the same area with no perceptible change in location. If, on the other hand, the initial grounding velocity was not negligible, computations of the total mass of the iceberg using only the above-water mass and ice/sea-water densities would have been in error.

\section{THE PROCESS OF ICEBERG GROUNDING}

For the smaller iceberg from the St. John's field study, pairs of aerial stereophotographs were taken on four different days and one photograph from each pair is shown in Figure 1. One notes from Figure 1 that the orientation of the iceberg changed between 10 and 14 June. This is apparent from the fact that the bay-like feature which was on the south-east side of the iceberg on 10 June shifted to the south by 14 June and remained there for the rest of the observation period. This change must have been the result of the iceberg refloating (or almost coming to the point of refloating) sometime during that $4 \mathrm{~d}$ period. In order to calculate the deterioration of the grounded iceberg prior to refloating, we need to estimate the amount of lift of the iceberg during initial grounding.

A free-floating iceberg drifting with a constant velocity is in a steady state with respect to the driving currents. When such an iceberg grounds in shallow water, its kinetic energy $E_{\mathrm{k}}$ is converted to potential energy $E_{\mathrm{p}}$ with some loss due to bottom friction $\left(E_{\mathrm{b}}\right)$. In addition, as the iceberg decelerates, the relative velocity between the decelerating iceberg and the propelling current creates a force which tends to drag the iceberg further. (A similar force for the above-water part of the iceberg is negligible.) If $E_{\mathrm{d}}$ is the work done by this force, the energy balance of a grounding iceberg may be expressed by the relationship

$$
E_{\mathrm{k}}+E_{\mathrm{d}}=E_{\mathrm{p}}+E_{\mathrm{b}} \text {. }
$$

The parameterization of each of the terms in Equation (3) is discussed below.

The net vertical force $F_{\mathrm{T}}$ acting on a floating iceberg is given by

$$
F_{\mathrm{T}}=F_{\mathrm{b}}+F_{\mathrm{g}}=0
$$

where $F_{\mathrm{b}}$ and $F_{\mathrm{g}}$ are the buoyancy and gravitational forces,

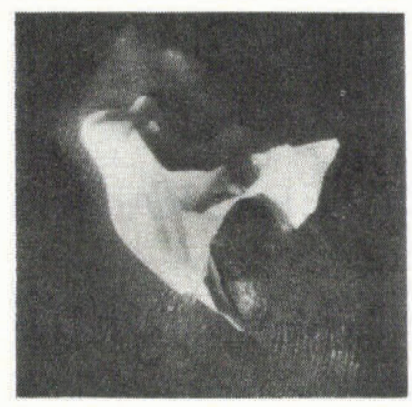

10 JUNE 1983

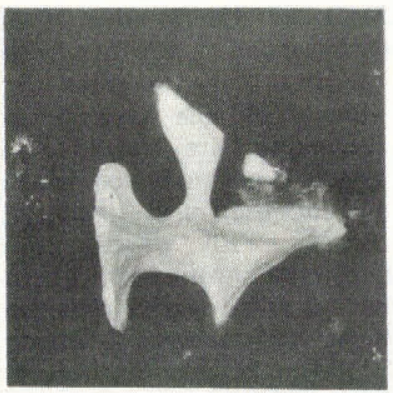

16 JUNE 1983

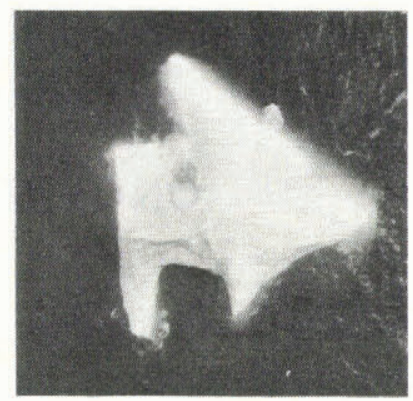

14 JUNE 1983

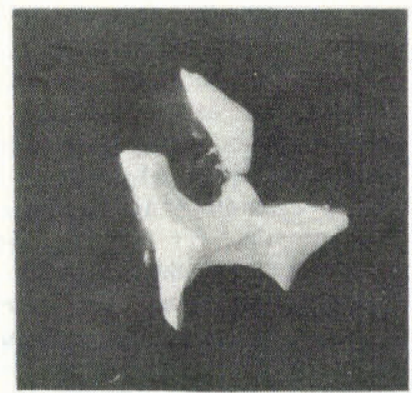

17 JUNE 1983

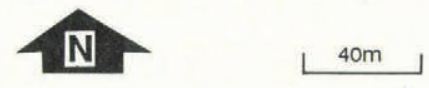

Fig. 1. Aerial photograph (from a stereo pair) of the iceberg grounded outside St. John's harbour, Newfoundland (from Venkatesh and others, 1985). North is indicated on the figure.

respectively. Using the standard parameterization of the two forces, Equation (4) may be written as

$$
F_{\mathrm{T}}=V_{\mathrm{u}} \rho_{\mathrm{w}} g-V_{\mathrm{t}} \rho_{\mathrm{i}} g
$$

where $V_{\mathrm{u}}$ and $V_{\mathrm{t}}$ are the under-water and total volume of the iceberg, respectively, $\rho_{w}$ and $\rho_{i}$ the densities of seawater and glacier ice, and $g$ the accelertion due to gravity. Let $A$ be the average cross-sectional area of the iceberg in the horizontal, and $S$ and $L$ lengths such that $V_{\mathrm{u}}=S A$ and $V_{\mathrm{t}}=L A$. Then, for a small displacement of the iceberg, the work done or the change in potential energy $\mathrm{d} E_{\mathrm{p}}$ may be written as

$$
\mathrm{d} E_{\mathrm{p}}=F_{\mathrm{T}} \mathrm{d} S=A g\left[\rho_{\mathrm{w}} S-\rho_{\mathrm{i}} L\right] \mathrm{d} S .
$$

Let $\Delta S$ be the net lift of the iceberg upon grounding. Then the change in potential energy of the grounded iceberg can be obtained by integrating Equation (6). This gives

$$
\begin{aligned}
E_{\mathrm{p}} & =\int_{S}^{S+\Delta S} A g\left[\rho_{\mathrm{w}} S-\rho_{\mathrm{i}} L\right] \mathrm{d} S \\
& =\left(A S \rho_{\mathrm{w}} g-A L \rho_{\mathrm{i}} g\right) \Delta S+\frac{1}{2} A g \rho_{\mathrm{w}}(\Delta S)^{2} .
\end{aligned}
$$

With the coefficient of the $\Delta S$ term identically equal to zero, Equation (7) simplifies to

$$
E_{\mathrm{p}}=\frac{1}{2} A g \rho_{\mathrm{w}}(\Delta S)^{2} .
$$

For small $\Delta S, A$ in Equation (8) equals the horizontal crosssectional area of the iceberg at the water line and will henceforth represent that value.

The work $E_{\mathrm{d}}$ done by the drag force of the water current on the decelerating iceberg may be written as (see Chari, 1979) 


$$
E_{\mathrm{d}}=\frac{\mathrm{C}_{\mathrm{d}} \rho_{\mathrm{w}} A_{\mathrm{p}} L_{\mathrm{s}} V^{2}}{6}
$$

where $C_{\mathrm{d}}$ is the drag coefficient, $A_{\mathrm{p}}$ is the projected area of the submerged part of the iceberg normal to the driving current, $L_{\mathrm{S}}$ is the length of scour on the ocean bottom, and $V$ is the initial steady-state velocity of the iceberg. The scour length $L_{\mathrm{S}}$ is the distance over which the drag force is in effect.

The kinetic energy $E_{\mathrm{k}}$ of the free-floating iceberg prior to grounding can be written as

$$
E_{\mathrm{k}}=\frac{1}{2} M V^{2}
$$

where $M$ is the mass of the iceberg. Assuming the ratio of the density of sea-water to that of glacier ice to be $8 / 7$ $\left(\rho_{\mathrm{W}}=1.017\right.$ tonnes $/ \mathrm{m}^{3}, \rho_{\mathrm{i}}=0.89$ tonnes $\left./ \mathrm{m}^{3}\right)$, the mass of the iceberg may also be written as

$$
M=7 \rho_{\mathrm{w}}(h-\Delta S) A
$$

where $h$ is a height such that $h A$ equals the observed above-water volume of the grounded iceberg. $(h-\Delta S) A$ then represents the above-water volume of the free-floating iceberg prior to grounding, since $\Delta S$ is the amount of lift upon grounding.

The energy loss $E_{\mathrm{b}}$ due to bottom friction is a function of the shear characteristics, in particular the shear strength, of the ocean bottom. Chari and others (1980) classified iceberg grounding into four categories ranging from horizontal ploughing where the ocean bottom is composed of very weak sediment, to full uplift where the ocean bottom is highly consolidated or almost rock. They also noted that in the latter case there is essentially no energy loss due to bottom friction and iceberg grounding will result in a travel of the iceberg up the slope until the available energy is converted to potential energy.

The ocean bottom in the vicinity of the grounded iceberg in question in the St. John's field study is composed of solid bedrock (Newfoundland Design Associates Limited, 1982). Hence, during the grounding of the iceberg, energy loss $E_{\mathrm{b}}$ due to bottom friction can be assumed to have been negligible and set equal to zero.

Using the expressions derived above for the various terms, Equation (3) may be written as

$$
\frac{7}{2} \rho_{\mathrm{w}}(h-\Delta S) A V^{2}+\frac{\mathrm{C}_{\mathrm{d}} \rho_{\mathrm{w}} A \mathrm{p}_{\mathrm{s}} V^{2}}{6}=\frac{1}{2} A g \rho_{\mathrm{w}}(\Delta S)^{2} .
$$

Dividing Equation (12) by $A$ and re-arranging, we get

$$
g(\Delta S)^{2}+7 V^{2} \Delta S-\left[7 h+\frac{C_{\mathrm{d}}{ }_{\mathrm{p}} L_{\mathrm{S}}}{3 A}\right] V^{2}=0 .
$$

With no bottom friction and full uplift of the iceberg, $\Delta S$ will equal $m L_{\mathrm{S}}$ where $m$ is the slope of the ocean floor. With $L=\Delta S / m$, Equation (13) becomes

$$
g(\Delta S)^{2}+\left[7 V^{2}-\frac{C_{\mathrm{d}} A V^{2}}{3 A m}\right) \Delta S-7 h V^{2}=0
$$

From Equation (14), $\Delta S$ can be determined if all the other parameters are known. For small $\Delta S$ the buoyancy loss $B_{\ell}$ due to iceberg lift is given by $\rho_{\mathrm{w}} A \Delta S$.

\section{DETERIORATION OF A GROUNDED ICEBERG}

In the case of a freely floating iceberg subjected to deterioration, there is continuous change in the position of the iceberg with respect to the water surface. At any given time the ratio of under-water volume to total volume of the iceberg is equal to the ratio of the density of glacier ice to that of sea-water. Thus, from a knowledge of the above-water volume of the iceberg, the total volume can be computed. And mass loss over a given period of time can be calculated from changes in the above-water mass of the iceberg.
However, when an iceberg is lifted up as a result of grounding, there is no continuous adjustment as it deteriorates further. However, all the deterioration mechanisms described earlier are still effective. In the grounded position the weight of the iceberg acting downwards is greater than the buoyancy force acting upwards. Deterioration proceeding in both the above-water and under-water parts of the iceberg, the iceberg will refloat when the net buoyancy loss due to lifting of the iceberg and deterioration under water becomes equal to the total loss in the weight of the iceberg. Comparison with observations of the time to refloat can be used as a measure of the effectiveness of the model in predicting the deterioration of a grounded iceberg. Once the iceberg becomes ungrounded, depending on the prevailing water currents and winds, it can drift into deeper water or be grounded again in shallower waters. In the latter case, unless the iceberg has sufficient time to reach a speed close to that of the prevailing water currents, the kinetic energy available for re-grounding will be small and hence the lift of the iceberg upon re-grounding will also be small. In general, if re-grounding occurs very close to the location of initial grounding, re-grounding forces would be small. For the iceberg in question in the St. John's field study, based on the fact that there was no significant change in the location, as opposed to orientation, of the iceberg between 10 and 14 June, one may conclude that the iceberg refloated only momentarily before grounding again. Thus, the velocity attained by the iceberg would have been small and one could assume that the force exerted during regrounding was negligible compared to that during the initial grounding.

For the grounded iceberg, deterioration at the water line is caused by wave erosion. Above the water line the mechanisms at play include insolation, forced air convection, and calving of the overhang caused by wave erosion. Below the water line the main deterioration mechanisms are forced water convection and buoyant convection.

As shown by earlier studies (El-Tahan and others, 1984), wave erosion is the most important deterioration mechanism, accounting for over $65 \%$ of total mass loss. With the iceberg grounded fairly close to shore, wave erosion will be mostly confined to that half of the iceberg facing the waves. Also, erosion effects will not be fully realized near the edges of the iceberg. Hence we will assume that the effective length over which wave erosion takes place is $80 \%$ of one-half the perimeter of the iceberg. The impact of these assumptions will be examined later in the paper.

\section{OBSERVATIONAL DATA}

Observational data collected in respect of the St. John's field study can be classified into iceberg-related data, meteorological data, and oceanographic data. Among iceberg-related data, the above-water iceberg dimensions were obtained from aerial stereophotographs taken on several days. The iceberg parameters extracted from these photographs included water-line perimeter, maximum length, width and height of the iceberg, above-water volume of the iceberg, and the horizontal cross-sectional area at the water line. The last two were obtained by establishing a crosssectional grid for each stereo pair, the grid being spaced to take into account major elevation changes on the iceberg. Further details of the iceberg-dimension calculations have been given in Venkatesh and others (1985). Other icebergrelated data included depth soundings near the iceberg (an indicator of iceberg draft) and side-scan sonar profiles of the iceberg. The quality of the side-scan data was such that only the general under-water shape of the iceberg could be determined from them. The profiles for the iceberg in question indicated that it had nearly vertical sides. Thus the under-water surface area, required in the computation of forced water and buoyant convection mass losses, is taken as $L d$ where $L$ is the iceberg perimeter at the water line and $d$ the depth of $0{ }^{\circ} \mathrm{C}$ water temperature below which there is no melting of the ice. Iceberg parameters measured and required as input to the deterioration model are shown in Table I.

The meteorological data consisted of wet- and dry-bulb air temperatures, barometric pressure, wind speed and 
TABLE I. ICEBERG PARAMETERS ESTIMATED FROM STEREOPHOTOGRAPHS. ALSO LISTED ARE OTHER PARAMETERS REQUIRED AS INPUT BY THE DETERIORATION MODEL OF EL-TAHAN AND OTHERS (1984). ALL DATES ARE IN JUNE 1983

\section{Day/Time}

$10 / 14.24 \quad 14 / 17.10 \quad 16 / 12.44$

$17 / 10.25$

$(G M T)$

\section{Maximum \\ length $(\mathrm{m})$}

130

Maximum

height $(\mathrm{m})$

42

25

26

Maximum

width (m)

Water-line perimeter (m)

Water-line crosssectional area $\left(\mathrm{m}^{2}\right)$

Above-water surface area $\left(\mathrm{m}^{2}\right)$

Under-water surface area* $\left(\mathrm{m}^{2}\right)$

Vertical component of under-water surface area* $\left(\mathrm{m}^{2}\right)$

Above-water volume $\left(1000 \mathrm{~m}^{3}\right)$ 65 46 38

Total mass ${ }^{\dagger}$ (1000 tonnes) 463 328

*Above depth of $0^{\circ} \mathrm{C}$ water temperature.

${ }^{+}$Computed from above-water volume assuming that the iceberg is floating.

direction, sky condition, and visibility. Details on the measurement of these parameters have been given in Venkatesh and others (1985).

Observations of oceanographic parameters relevant to iceberg deterioration consisted of sea-surface temperature, sea-temperature profiles, wave height and period, and ocean currents. Again, further details on the measurements of the above parameters have been given in Venkatesh and others (1985). Ocean-bottom characteristics in the vicinity of the iceberg have been discussed earlier in the paper. From hydrographic charts, the ocean-bottom slope at the location of the iceberg is estimated to be $30 \mathrm{~m}$ in $2.5 \mathrm{~km}$ or 1 in
83.3. The meteorological and oceanographic conditions required as input to the iceberg-deterioration model are given in Table II. And, as discussed in Venkatesh and others (1985), a mean water current of $0.1 \mathrm{~m} / \mathrm{s}$ was used in the computation of mass losses due to forced water convection.

The one piece of data that is not available, but required to estimate iceberg lift upon grounding, is the velocity of the iceberg prior to grounding. In the absence of these data, we will need to determine the initial velocity or the range of velocities for which the model-simulated time of iceberg re-flotation agrees with that observed. The initial velocity or velocities thus determined will then need to be validated through other means.

The date of re-flotation of the iceberg, which in this case is indicated by a significant change in its orientation, was determined from daily polaroid photographs of the north, south, east, and west faces of the iceberg. These photographs were taken from the field-study vessel located $230 \mathrm{~m}$ (1/8 nautical mile) from the iceberg. The time of reflotation of the iceberg could have been determined more accurately if the photographs had been taken at more frequent intervals. However, this was not the case as the original purpose of the St. John's field study was to study the daily deterioration of the iceberg as it remained grounded.

\section{RESULTS AND DISCUSSION}

The first task is to compute the deterioration of the iceberg while it is grounded. The aerial stereophotographs indicated that there was a significant change in the orientation of the iceberg between 10 and 14 June. Polaroid photographs of the iceberg taken daily showed that this shift had occurred between 11 and 12 June. Thus, in the absence of a precise knowledge of the velocity of the iceberg prior to grounding, we need to determine, using the various deterioration mechanisms and the formulations for the lifting of the iceberg upon grounding, the velocity or range of velocities of the iceberg for which re-flotation will occur between 11 and 12 June. Assuming the iceberg to remain grounded, Table IIIa gives the daily contributions of the various mechanisms to the deterioration of the iceberg over the period 10-14 June. The numbers in this table, as noted earlier, are based on wave erosion, and hence calving, occurring over $80 \%$ of the half of the iceberg facing the waves. Also, wave erosion is split equally above and below the water line. From Table IIIa it is seen that wave erosion is the most significant deterioration mechanism followed by calving and then forced water convection. Table IIIb gives, on a daily basis, the cumulative iceberg mass loss and the buoyancy loss due to deterioration. These values are derived from the various losses listed in Table IIIa.

The lifting of the iceberg upon grounding can be computed from Equation (14) for various iceberg velocities prior to grounding. In Equation (14), $A_{p}$ is obtained as the product of the length of the iceberg at water line and the iceberg draft given by water depth. Here we have made use

\section{TABLE II. ENVIRONMENTAL CONDITIONS AT THE LOCATION OF THE ICEBERG FOR}

\section{THE PERIOD 10-17 JUNE 1983}

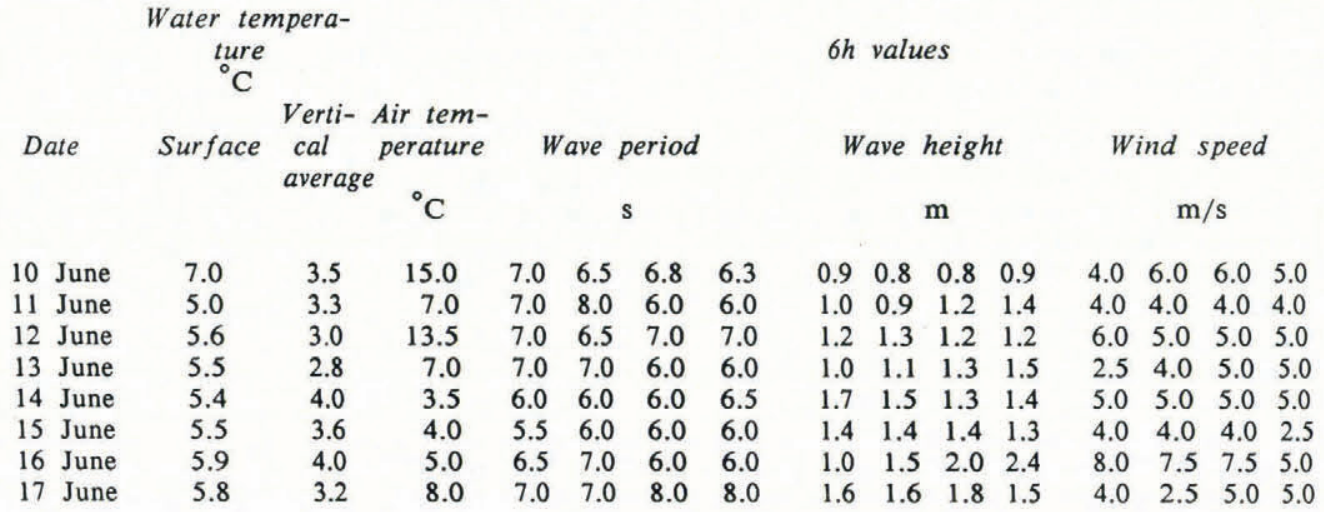


TABLE IIIa. ABOVE-WATER AND UNDER-WATER VOLUME LOSSES OF THE GROUNDED ICEBERG DUE TO VARIOUS DETERIORATION MECHANISMS. ALL DATES ARE IN 1983. WAVE EROSION IS EFFECTIVE OVER $80 \%$ OF THE SEAWARD HALF OF THE ICEBERG

Loss mechanism

Volume loss above
water line $\left(\mathrm{m}^{3}\right)$

Volume loss below water line $\left(\mathrm{m}^{3}\right)$
Insolation

Forced air convection

Wave erosion

Calving

Buoyant convection

Forced water convection

Wave erosion
10-11 June 11-12 June 12-13 June 13-14 June

$\begin{array}{rrrr}205 & 190 & 177 & 390 \\ 647 & 231 & 511 & 204 \\ 7630 & 6544 & 7837 & 6902 \\ 4160 & 4274 & 4019 & 3962 \\ & & & \\ 546 & 466 & 381 & 319 \\ 2747 & 2408 & 2041 & 1756 \\ 7630 & 6544 & 7837 & 6902\end{array}$

TABLE IIIb. CUMULATIVE ICEBERG VOLUME/MASS LOSS AND BUOYANCY LOSS TO DATE DUE TO VARIOUS DETERIORATION MECHANISMS. ALL DATES ARE IN 1983

$\begin{array}{lcccc} & 10-11 \text { June } & 10-12 \text { June } & 10-13 \text { June } & \text { 10-14 June } \\ \text { Iceberg volume loss }\left(\mathrm{m}^{3}\right) & 23565 & 44222 & 67025 & 87460 \\ \text { Iceberg mass loss (tonnes) } & 20973 & 39358 & 59652 & 77839 \\ \begin{array}{c}\text { Buoyancy loss due to } \\ \text { deterioration (tonnes) }\end{array} & 11109 & 20687 & 31120 & 40250\end{array}$

TABLE IIIC. CUMULATIVE BUOYANCY LOSS TO DATE DUE TO DETERIORATION AND LIFTING OF THE ICEBERG AS A FUNCTION OF THE ICEBERG VELOCITY PRIOR TO GROUNDING

\author{
Cumulative buoyancy loss \\ tonnes \\ (due to (deterioration below water line + iceberg lift) \\ Refloat date \\ in \\ June
}

$\begin{array}{rlrccccc}\begin{array}{c}V \\ \mathrm{~m} / \mathrm{s}\end{array} & \begin{array}{l}\Delta S \\ \mathrm{~m}\end{array} & \begin{array}{c}B_{\ell} \\ \text { tonnes }\end{array} & 10-11 \text { June } & \text { 10-12 June } & 10-13 \text { June } & 10-14 \text { June } & \\ 0.60 & 2.354 & 21709 & 32818 & 42396 & 52829 & 61969 & 12-13 \\ 0.50 & 1.885 & 17384 & 28493 & 38071 & 48504 & 57634 & 11-12 \\ 0.40 & 1.436 & 13242 & 24351 & 33929 & 44362 & 53492 & 11-12 \\ 0.30 & 1.025 & 9452 & 20561 & 30139 & 40572 & 50702 & 10-11\end{array}$

of the observation that the iceberg profile under water is nearly vertical. $A$, the cross-sectional area of the iceberg at the water line is obtained from stereophotographs. Based on earlier studies (Fenco Newfoundland Limited, 1982), the value for the drag coefficient $C_{d}$ is taken as 1.0 .

Table IIIc gives the cumulative buoyancy losses due to lifting of the iceberg and under-water deterioration. The buoyancy loss $B_{\ell}$ due to lifting alone is also given in the table for various initial velocities of the iceberg. Figure 2 shows a plot of the cumulative buoyancy loss and total iceberg mass loss as a function of time and for various initial velocities of the iceberg. The iceberg will refloat when the cumulative buoyancy loss becomes less than the iceberg mass loss (from Table IIIb). Thus, for the iceberg to refloat during the $24 \mathrm{~h}$ period between 11 and 12 June, as suggested by observations, its velocity prior to grounding must have been $0.4-0.5 \mathrm{~m} / \mathrm{s}$. With no observational data available on the drift velocity of the iceberg prior to grounding, we can only discuss the appropriateness of the above-determined velocities.

An analysis of the drift speeds of 68 icebergs in the Newfoundland/Labrador Sea areas and the water currents associated with these icebergs was carried out by El-Tahan and others (1983). It was found that the icebergs generally travel in the range of $0.1-0.5 \mathrm{~m} / \mathrm{s}$ with the velocities going outside this range about $10 \%$ of the time. Also, correlating iceberg-drift speed with water-current velocities, they found that drift speeds of icebergs were about 1.5 times the water-current velocity at $15 \mathrm{~m}$ depth and about twice that at $50 \mathrm{~m}$ depth. Similar correlation studies by Soulis (unpublished) yielded a factor of 2.5 between iceberg-drift speed and water current at $13 \mathrm{~m}$ depth. In the St. John's field study, on 8 June, current speeds of $0.045-0.1 \mathrm{~m} / \mathrm{s}$ were measured at $15 \mathrm{~m}$ and $0.09-0.25 \mathrm{~m} / \mathrm{s}$ at a depth of $40 \mathrm{~m}$. The corresponding values on 12 June were $0.08-0.14 \mathrm{~m} / \mathrm{s}$ and $0.12-0.25 \mathrm{~m} / \mathrm{s}$, respectively. Thus, given that the $15 \mathrm{~m}$ currents are less than those at $40 \mathrm{~m}$, one will get vastly different iceberg-drift velocities if the above-mentioned correlations for the two depths are used, thereby casting some doubt on the validity of these correlations. In spite of this remark, if one uses a factor of 2 on the $40 \mathrm{~m}$ current, then iceberg-drift speed of up to $0.5 \mathrm{~m} / \mathrm{s}$ (corresponding to a current speed of $0.25 \mathrm{~m} / \mathrm{s}$ ) prior to grounding would have been possible. Thus one may conclude that the derived range of $0.4-0.5 \mathrm{~m} / \mathrm{s}$ (see Table IIIc) for the velocity of the iceberg prior to grounding is quite feasible. One may also note from Table IIIb and $\mathrm{c}$ that even for a velocity of $0.3 \mathrm{~m} / \mathrm{s}$ the refloating of the iceberg occurs very close to the end of the $24 \mathrm{~h}$ period between 10 and 11 June. Thus, effectively, the iceberg will refloat during the 11-12 June period for initial velocities in the range $0.3-0.5 \mathrm{~m} / \mathrm{s}$.

Table IV and Figure 3 show the results assuming that wave erosion and calving occur over $100 \%$ of that half of the iceberg facing the waves. Under these conditions, the iceberg will refloat during the 11-12 June period for pregrounding velocities in the range of $0.4-0.6 \mathrm{~m} / \mathrm{s}$. For a 


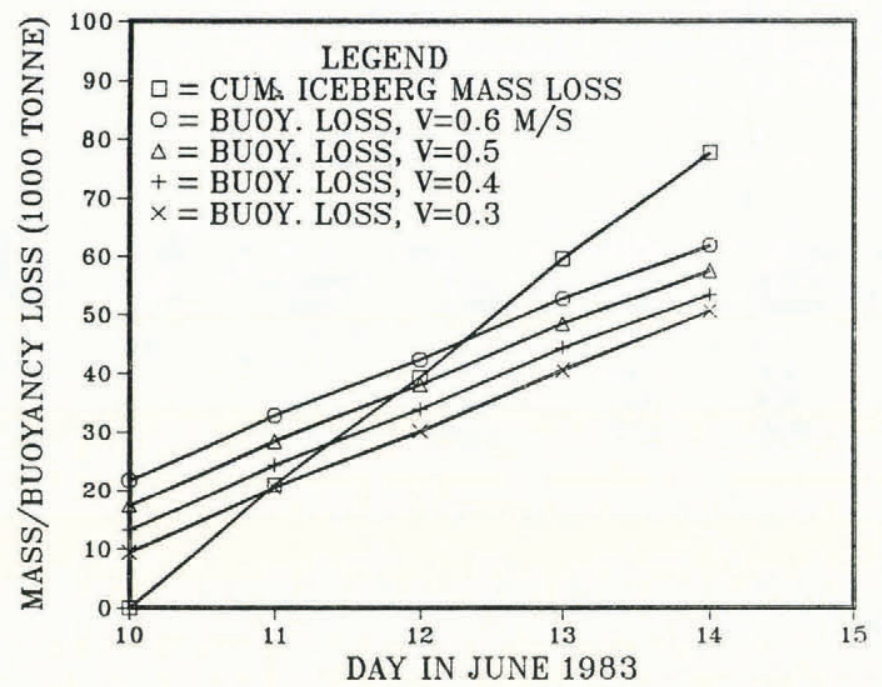

Fig. 2. Cumulative mass and buoyancy losses of the iceberg versus time. Buoyancy losses are given for various pre-grounding velocities of the iceberg. Wave erosion is effective over $80 \%$ of the water-line perimeter on the seaward half of the iceberg.

velocity of $0.6 \mathrm{~m} / \mathrm{s}$ re-flotation occurs fairly late in the $24 \mathrm{~h}$ period (Fig. 3). Thus, in this case also, re-flotation of the iceberg occurs during the 11-12 June period for the expected range of initial velocities of the iceberg.

Having determined the time of re-flotation of the iceberg, the next task is to compute its subsequent deterioration. As discussed earlier, the forces involved in re-groundings are negligible and the iceberg can be treated as a floating one in respect to its response to further deterioration. For the purpose of determining this deterioration, the iceberg characteristics will be initialized to the beginning of the day on 12 June. The above-water volume on 10 June was known from the stereophotographs $\left(116000 \mathrm{~m}^{3}\right)$. The above-water volume loss for the period 10-12 June can be determined from Table IIIa $\left(23880 \mathrm{~m}^{3}\right)$. The difference is then the above-water volume of the iceberg on 12 June $\left(92120 \mathrm{~m}^{3}\right)$. Length and area parameters required as model input and observed on 10 June are multiplied respectively by the factors $(92.12 / 116)^{1 / 3}$ and $(92.12 / 116)^{2 / 3}$ to obtain their values corresponding to 12 June. The perimeter of the iceberg at the water line obtained in this manner is likely to be an underestimate, since the observed value on 14 June was $571 \mathrm{~m}$, much higher than that for 10 June. It is clear that when the iceberg refloated there was a considerable change in its orientation which resulted in a significant increase in the water-line perimeter. In the absence of a precise knowledge of the water-line perimeter after re-flotation on 12 June, we will use the value observed on 14 June. Use of this value will lead to a lower estimate of deterioration since the water-line perimeter on 12 June was most likely higher than that on 14 June. Figure 4 shows a comparison of observed and predicted iceberg mass on various dates. The predictions were obtained using the model of El-Tahan and others (1984). The curve marked "predicted (12-17)-1" is obtained with the water-line perimeter computed from the

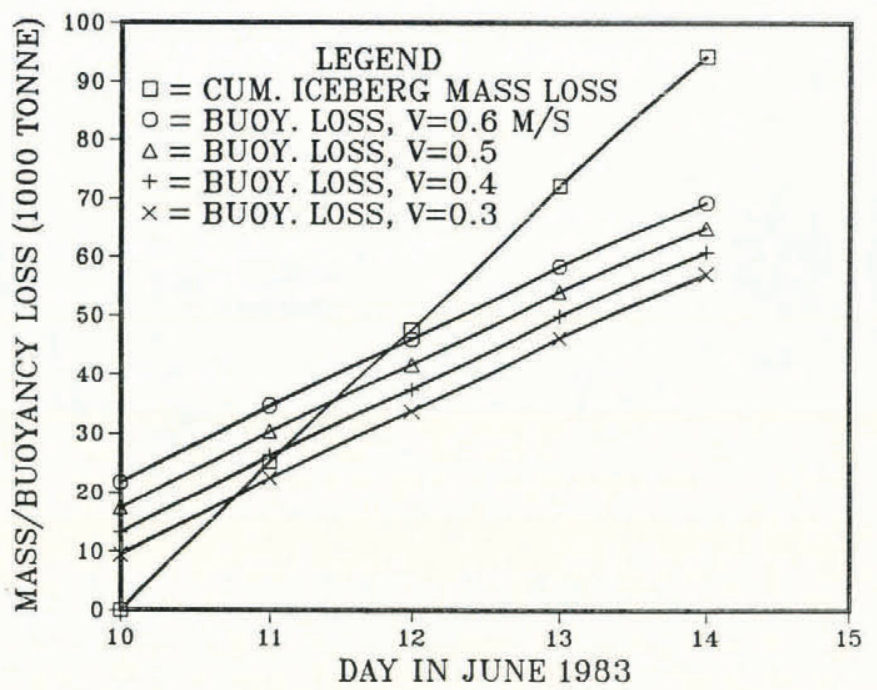

Fig. 3. Same as Figure 2 but wave erosion is effective over $100 \%$ of the water-line perimeter on the seaward half of the iceberg.

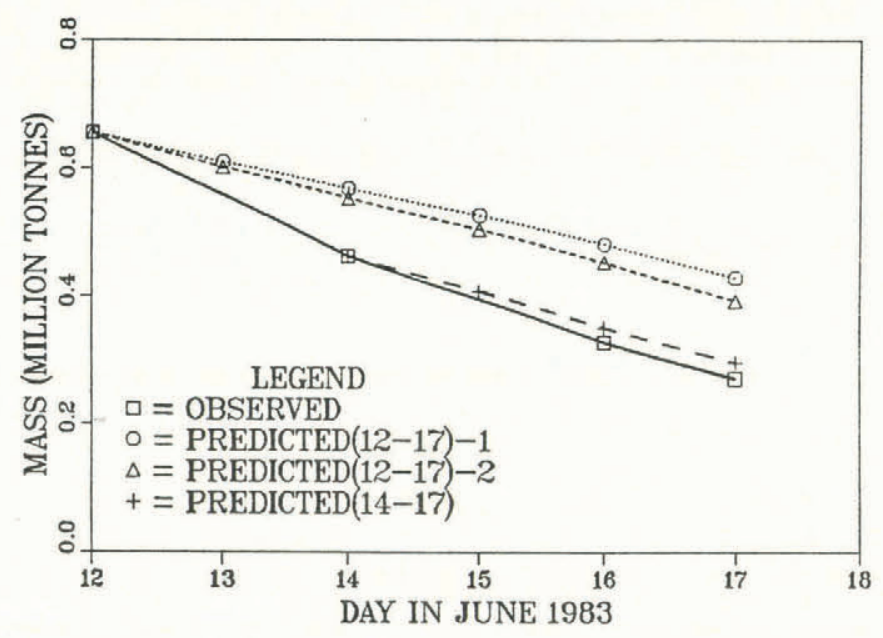

Fig. 4. Observed and predicted mass reduction of the iceberg following its re-flotation. See text for explanation of the different curves.

observed value on 10 June as described above. The curve marked "predicted $(12-17)-2$ " is obtained using the waterline perimeter observed on 14 June. Also shown in the figure is the simulation for the period 14-17 June obtained by initializing the model with observed data from 14 June and which agrees very well with observations.

One notes from Figure 4 that the slope of the "observed" iceberg-mass curve is much greater during the period 12-14 June than it is during the period 14-17 June. This difference accounts for much of the differences between the observed and model-simulated iceberg mass as a function of time. With the total mass of the iceberg on

TABLE IV. SAME AS TABLE IIIC EXCEPT WAVE EROSION IS EFFECTIVE OVER 100\% OF THE SEAWARD HALF OF THE ICEBERG

\begin{tabular}{|c|c|c|c|c|c|c|c|}
\hline \multirow[b]{2}{*}{$\begin{array}{c}V \\
\mathrm{~m} / \mathrm{s}\end{array}$} & \multirow[b]{2}{*}{$\begin{array}{r}\Delta S \\
m\end{array}$} & \multirow[b]{2}{*}{$\begin{array}{l}B_{\ell} \\
\text { tonnes }\end{array}$} & \multirow[b]{2}{*}{ 10-11 June } & \multicolumn{2}{|c|}{$\begin{array}{c}\text { Cumulative buoyancy loss } \\
\text { tonnes }\end{array}$} & \multirow[b]{2}{*}{ 10-14 June } & \multirow{2}{*}{$\begin{array}{c}\text { Refloat date } \\
\text { in } \\
\text { June }\end{array}$} \\
\hline & & & & 10-12 June & 10-13 June & & \\
\hline 0.60 & 2.354 & 21709 & 34757 & 45999 & 58425 & 69309 & $11-12$ \\
\hline 0.50 & 1.885 & 17384 & 30432 & 41674 & 54100 & 64984 & $11-12$ \\
\hline 0.40 & 1.436 & 13242 & 26290 & 37532 & 49958 & 60842 & $11-12$ \\
\hline 0.30 & 1.025 & 9452 & 22500 & 33742 & 46168 & 57052 & $10-11$ \\
\hline
\end{tabular}




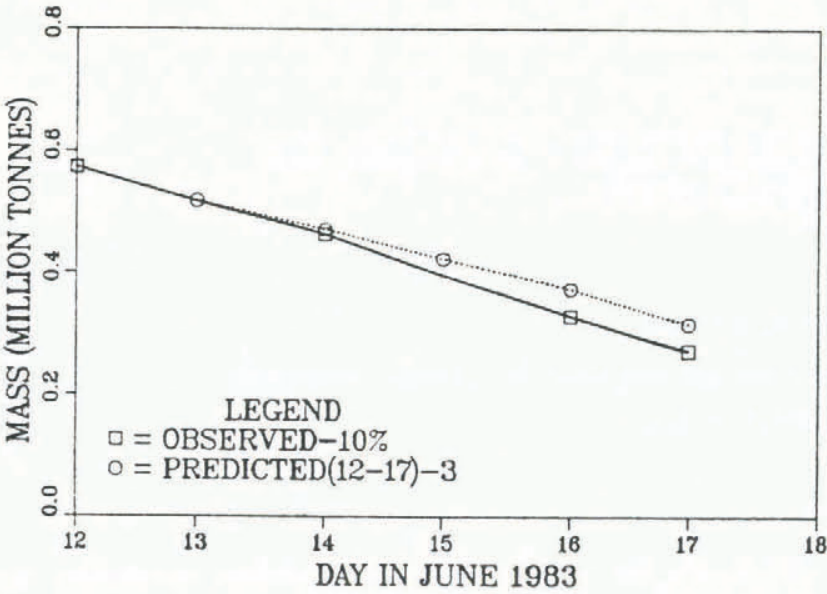

Fig. 5. Observed and predicted mass reduction of the iceberg following its re-flotation. A $10 \%$ overestimate is allowed for in the observed iceberg mass on 10 June 1983.

12 June, when it refloats, being calculated from its abovewater volume, any error in the latter is magnified eight-fold. The above-water volume on 12 June is itself derived from the observed above-water volume on 10 June and above-water volume loss during the period 10-12 June. It would be instructive to look at the results based on a $10 \%$ overestimate in the observed above-water volume of the iceberg on 10 June. All other parameters are the same as those for the curve marked "predicted $(12-17)-2^{\text {" }}$ in Figure 4. Thus, the above-water volume on 10 June is $104400 \mathrm{~m}^{3}$ and the iceberg mass on 12 June, after allowing for deterioration losses, is 573000 tonnes. Figure 5 shows the results of this analysis and it is clear that the results are much improved. It is also worth noting that modelsimulated iceberg mass on dates other than 12 June is within about $15 \%$ of the observed value.

\section{SUMMARY AND CONCLUSIONS}

In this paper the deterioration of a grounded iceberg has been described. The deterioration occurs in two stages. The first stage consists of the deterioration of the grounded iceberg up to the point of refloating. In the second stage, deterioration beyond the point of refloating is considered. In respect to the first stage, expressions have been derived for the buoyancy loss of the iceberg as a result of lifting upon grounding, the amount of lift being a function of the iceberg velocity prior to grounding. A knowledge of this buoyancy loss is important in establishing the amount of mass that the iceberg has to lose before it can refloat.

The model simulations have been compared with data obtained from a 1983 field study conducted on an iceberg grounded outside St. John's harbour, Newfoundland. With no data on the pre-grounding velocity of the iceberg being available, the model-derived date of re-flotation of the iceberg has been compared with observed data (from daily polaroid photographs of the iceberg) for a range of velocities. Other studies on correlations of iceberg velocities with water currents at different depths have been used to substantiate the iceberg velocities used. The model-derived date of re-flotation has been found to agree with the observed date for pre-grounding ice velocities in the range of $0.3-0.5 \mathrm{~m} / \mathrm{s}$. Model performance can be better evaluated with the availability of data on iceberg velocity prior to grounding, as also data defining more precisely the time of re-flotation of the iceberg.
In respect to the second stage, the deterioration of the iceberg has been based on the model developed by El-Tahan and others (1984). The model was initialized for the time of re-flotation with data observed on 10 June adjusted to account for deterioration during the period in which the iceberg remained grounded.

Model results were improved with the use of iceberg perimeter at the water line as observed on 14 June. the basis for the use of these data was the apparently significant increase in the perimeter of the iceberg at the water line at the time of re-flotation. Best agreement was obtained when results from the model initialized with data on 14 June were compared with deterioration during the period 14-17 June.

An error analysis performed indicated the need for accurate estimation of iceberg mass, particularly when it is calculated from only the above-water part.

\section{ACKNOWLEDGEMENTS}

The author wishes to thank $\mathbf{M r} \mathbf{R}$. Jessup, his colleague, and Dr T.R. Chari, Associate Dean of Engineering, Memorial University of Newfoundland, for many useful discussions during the course of this work. The review of the original manuscript by Mrs M. El-Tahan and $\mathrm{Mr} \mathbf{H}$. El-Tahan of Fenco Newfoundland Limited is gratefully acknowledged.

\section{REFERENCES}

Chari, T.R. 1979. Geotechnical aspects of iceberg scours on ocean floors. Canadian Geotechnical Journal, Vol. 16, No. 2, p. $379-90$

Chari, T.R., and others. 1980. Environmental factors affecting iceberg scour estimates, by T.R. Chari, G.R. Peters, and K. Muthukrishnaiah. Cold Regions Science and Technology, Vol. 1, Nos. 3-4, p. 223-30.

El-Tahan, $M$. and others. 1983. Forecast of iceberg ensemble drift, by M. El-Tahan, H.W. El-Tahan, and S. Venkatesh. 15th Annual Offshore Technology Conference, Houston, Texas, U.S.A., May 2-5, 1983. Proceedings, p. $151-58$.

El-Tahan, M., and others. 1984. Validation and quantitative assessment of the deterioration mechanisms of Arctic icebergs, by M. El-Tahan, S. Venkatesh, and H. El-Tahan. Third International Offshore Mechanics and Arctic Engineering Symposium, New Orleans, U.S.A. Proceedings. Vol. 111 , p. 18-25.

Fenco Newfoundland Limited. 1982. Factors controlling iceberg drift and design of an iceberg drift prediction system. Downsview, Ontario, Environment Canada. Atmospheric Environment Service.

Newfoundland Design Associates Limited. 1982. St. John's sewage disposal study. Vol. II. Physical environment of Freshwater Bay. St. John's, Government of Newfoundland and Labrador. Department of Municipal Affairs.

Soulis, E.D. Unpublished. Modelling of iceberg drift using wind and current measurements at a fixed station. [M. Eng. thesis, Memorial University of Newfoundland, 1976.]

Venkatesh, S., and others. 1985. An Arctic iceberg deterioration field study and model simulations, by $\mathrm{S}$. Venkatesh, M. El-Tahan, and P.T. Mitten. Annals of Glaciology, Vol. 6, p. 195-99.

White, F.M., and others. 1980. Theoretical estimates of the various mechanisms involved in iceberg deterioration in the open ocean environment, by F.M. White, M.L. Spaulding. and L. Gominho. Washington, DC, U.S. Department of Transportation. United States Coast Guard. (Report No. CG-D-62-80.) 